Daniel Lamarca Marques

\title{
Detecção de Escapamentos de Gás Natural
}

Monografia ApresentadA ao Programa de Pós-GraduaçÃo EM ENGENHARIA MECÂNICA DA PUC-RIO COMO REQUISITO PARCIAL PARA OBTENÇÃO DO TÍTULO DE ESPECIALISTA EM ENGENHARIA DE DUTOS. APROVADA PELA COMISSÃO EXAMINADORA ABAIXO ASSINADA.

Orientador: Professor José Luiz de França Freire Co-orientador: Eng. Vitor Hugo dos Santos Pena
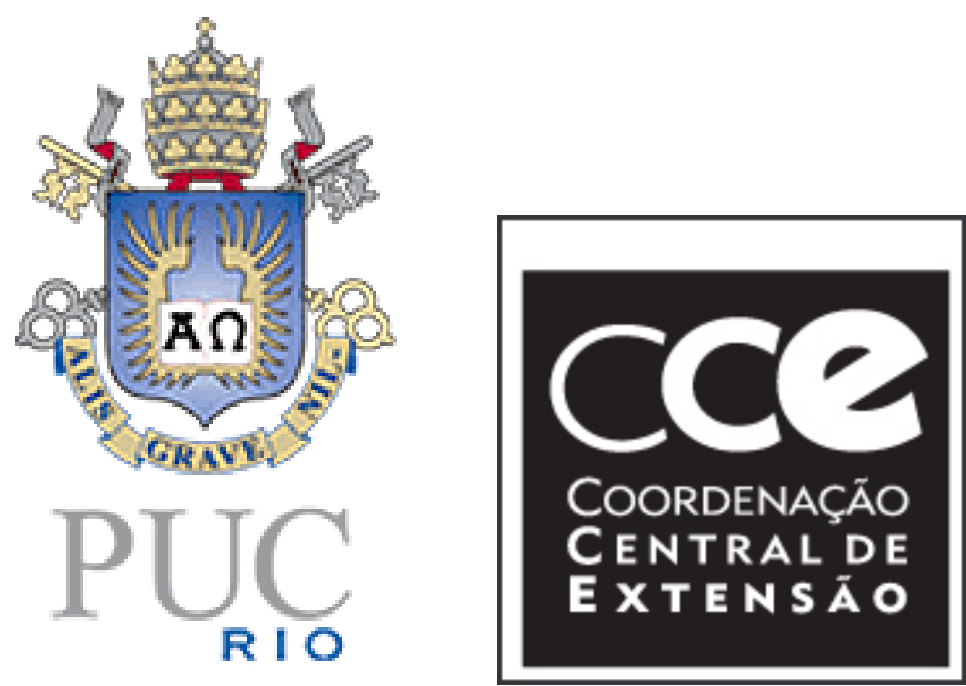

Rio de Janeiro

31 de Outubro de 2017 


\section{AGRADECIMENTOS}

Ao Eng. Vitor Hugo dos Santos Pena e à equipe de manutenção pela disponibilidade e acompanhamento nas atividades em campo, ao professor José Luiz de França Freire pela orientação nesta monografia, aos meus pais, aos familiares e amigos pelo incentivo ao longo do curso. 


\section{RESUMO}

O sistema de distribuição de gás natural é composto por uma grande rede de dutos e por determinados equipamentos que precisam de constantes manutenções preventivas. Existem diversos reguladores, válvulas, filtros, medidores e conversores compostos na rede que precisam de inspeções e revisões regulares para manter o funcionamento em dia. Além disso, é necessária uma atividade de detecção periódica para identificar qualquer escapamento de gás com antecedência. $O$ principal objetivo é garantir a segurança do sistema de distribuição de gás.

Neste trabalho são apresentados a tecnologia aplicada nos equipamentos portáteis e os diferentes tipos de sensores que esses equipamentos podem utilizar para identificar a presença do gás natural no ambiente.

Com o auxílio de uma planta cartográfica, o serviço de detecção é realizado passando por cima das redes (tubulações enterradas) utilizando os sensores que detectam o gás natural através do metano. Quando um sensor demonstra elevada concentração de metano no ambiente, o trecho é analisado e estudado para descobrir o local exato da tubulação onde ocorre o vazamento de gás.

Essa análise é feita realizando furos no trecho e medindo o volume percentual de metano em cada um desses furos. Utilizando a técnica da aproximação sucessiva simples é possível localizar o furo do trecho com o maior índice de volume percentual de metano e assim concluir com certa precisão que naquele ponto está o vazamento de gás natural.

Palavras-chave: gás natural, planta cartográfica, tubulações enterradas, volume percentual. 


\section{ABSTRACT}

The natural gas distribution system consists of a large network of ducts and certain equipment that need constant preventive maintenance. There are several regulators, valves, filters, meters and converters compounds in the network that require inspections and regular reviews to keep operating days. Furthermore, it is necessary periodical activity detection to identify any gas leakage in advance. The main objective is to ensure the safety of the gas distribution system.

This paper presents the technology applied in portable devices and the different types of sensors that such equipment can be used to identify the presence of natural gas in the environment.

With the aid of a cartographic plant, the detection service is performed by passing over the networks (buried pipes) using the sensors that detect the natural gas through the methane. When a sensor shows a high concentration of methane in the environment, the section is analyzed and studied to find out the exact location of the pipeline where the gas leak occurs.

This analysis is done by drilling holes in the stretch and measuring the percentage volume of methane in each of these holes. Using the technique of simple successive approximation it's possible to locate the hole of the stretch with the highest percentage volume of methane and thus conclude with some precision that the leakage of natural gas is at that point.

Keywords: natural gas, cartographic plant, buried pipes, percentage volume. 


\section{SUMÁRIO}

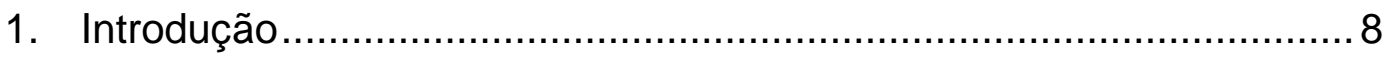

2. Equipamentos do sistema de distribuição de gás ..............................11

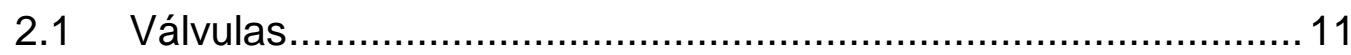

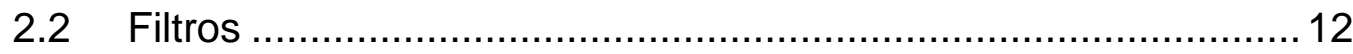

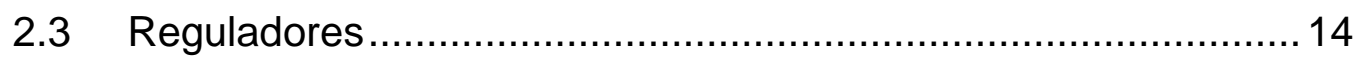

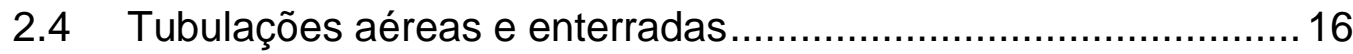

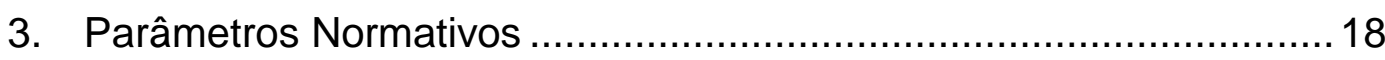

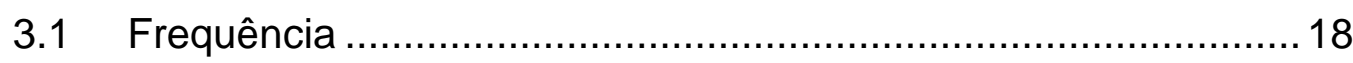

3.2 Classificação dos níveis de fuga .............................................. 19

3.3 Prazos de resolução das fugas ................................................ 19

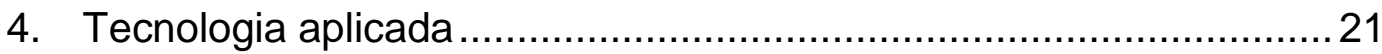

4.1 Tipos de sensores utilizados no serviço de detecção ..................21

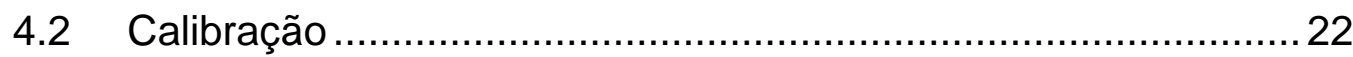

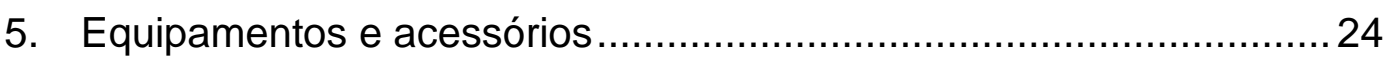

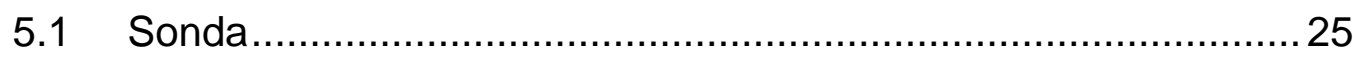

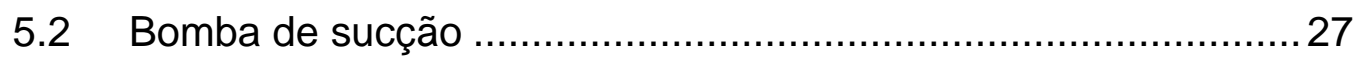

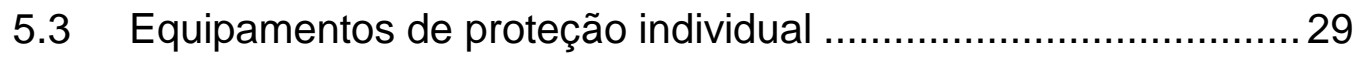

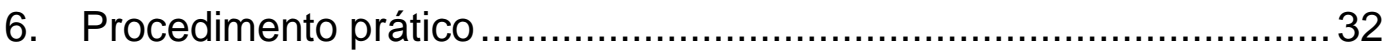

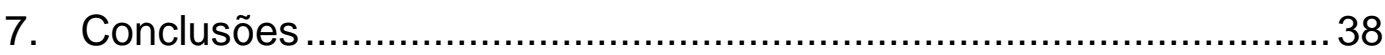

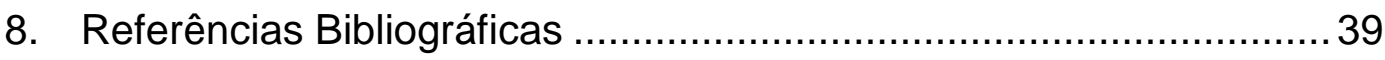




\section{LISTA DE FIGURAS}

FIGURA 1 - EXEMPLO DE UMA VÁLVULA DE BLOQUEIO. ............................ 11

FIGURA 2 - EXEMPLOS DE FILTROS. ................................................ 13

FIGURA 3 - REGULADOR DE AÇÃO DIRETA ........................................ 15

FIGURA 4 - REGULADOR PILOTADO. [1] ............................................. 16

FIGURA 5 - TUBULAÇÕES AÉREAS.................................................. 17

FIGURA 6 - ACESSÓRIOS DO EX-TEC HS 680 DA SEWERIN. [5] ....................23

FIGURA 7 - SENSOR EX-TEC HS 680 DA SEWERIN. [5] .............................. 25

FIGURA 8 - PRIMEIRO FILTRO. ....................................................... 26

FIGURA 9 - SEGUNDO FILTRO. ..................................................... 27

FIGURA 10 - TERCEIRO FILTRO FICA DENTRO DO EX-TEC HS $680 \ldots \ldots \ldots \ldots \ldots . . \ldots 27$

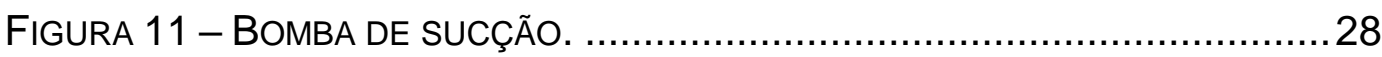

FIGURA 12 - CAPACETE. .......................................................... 29

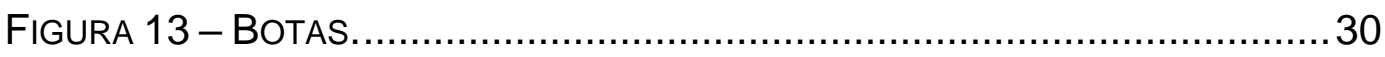

FIGURA 14 - COLETE RETRORREFLEXIVO (FRENTE E VERSO). ....................... 30

FIGURA 15 - ABAFADOR E PROTETOR DE INSERÇÃO. ................................... 30

FIGURA 16 - ÓCULOS DE IMPACTO. .................................................. 31

FIGURA 17 - EQUIPE REALIZANDO O SERVIÇO DE DETECÇÃO DE ESCAPAMENTOS.

FIGURA 18 - PLANTA IMPRESSA DE UM APLICATIVO CARTOGRÁFICO QUE AUXILIA NA LOCALIZAÇÃO DAS TUBULAÇÕES..............................................33

FIGURA 19 - MEDIDOR MOSTRANDO UMA LEITURA DE 5 PARTES POR MILHÃO DE METANO.............................................................................. 34

FIGURA 20 - MEDIDOR MOSTRANDO UMA LEITURA DE 750 PARTES POR MILHÃO

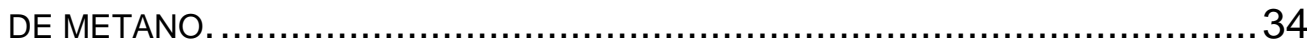

FIGURA 21 - UTILIZAÇÃO DE CHAVE DE FENDA PARA AUXILIAR NA ABERTURA DE BUEIROS IMPERMEÁVEIS............................................................. 35

FIGURA 22 - DESENHO ESQUEMÁTICO QUE REPRESENTA A SITUAÇÃO REAL DE UM DUTO ENTERRADO COM VAZAMENTO. .........................................35

FIGURA 23 - DESENHO ESQUEMÁTICO APÓS A REALIZAÇÃO DOS FUROS E A MEDIÇÃO DOS VOLUMES PERCENTUAIS DE GÁS NATURAL EM CADA UM DELES.

FIGURA 24 - MEDIÇÃO DE 22\% DE VOLUME PERCENTUAL DE GÁS NO FURO, O MAIOR DO TRECHO. 
LISTA DE TABELAS

TABELA 1 - COMPOSIÇÃO TÍPICA DO GÁS NATURAL. [1] …............................ 8

TABELA 2 - QUANTIDADE DE POLUENTES GERADOS EM LIBRAS/BILHÃO BTU POR COMBUSTÍVEL FÓSSIL. [1] ......................................................... 9

TABELA 3 - FREQUÊNCIAS QUE DEVEM SER REALIZADAS AS DETECÇÕES. .........18 


\section{NOMENCLATURA}

MPO Máxima pressão de operação bar

Vol Volume percentual $\quad \%$ 


\section{1.}

\section{Introdução}

O gás natural é resultado de um processo de degradação da matéria orgânica em profundos reservatórios no subsolo, ou seja, ele é um combustível fóssil e só pode ser retirado através de perfurações, assim como é feito com o petróleo nas profundezas do mar. A tabela 1 apresenta a composição típica de gás natural conforme informado abaixo [1].

\begin{tabular}{|c|c|}
\hline Composto químico & $\%$ volume \\
\hline Metano & 89,0 \\
\hline Etano & 6,0 \\
\hline Propano & 1,8 \\
\hline $\mathrm{C}_{4}+$ & 1,0 \\
\hline $\mathrm{CO}_{2}$ & 1,5 \\
\hline $\mathrm{N}_{2}$ & 0,7 \\
\hline
\end{tabular}

O gás natural é um combustível que gera menos poluição à atmosfera se comparado aos demais, além disso, é inodoro e incolor. Dentre os combustíveis fósseis, ele é o que gera a menor taxa de emissão de gás carbônico $\left(\mathrm{CO}_{2}\right)$, contribuindo bastante para a redução do efeito estufa em comparação com os outros combustíveis energéticos e podendo oferecer uma contribuição imediata à solução desse problema. No Brasil, não havia legislações ambientais mais rigorosas que obrigassem a indústria a levar em conta os custos ambientais do seu consumo de energia e, como consequência, não houve grandes investimentos e incentivos à penetração do gás natural na matriz energética do segmento industrial. Porém, em 1986, o Conselho Nacional do Meio Ambiente (Ibama) publicou a Resolução 001/86, que traz uma definição de impacto ambiental e enumera as atividades passíveis de enquadramento como impactantes [2].

Considerando-se o ponto de vista ambiental, o gás natural é muito melhor do que os outros combustíveis fósseis por ser, basicamente, composto de metano $\left(\mathrm{CH}_{4}\right)$, uma molécula feita de um átomo de carbono e quatro átomos de hidrogênio. Quando o metano é completamente queimado, os principais produtos da combustão são dióxido de carbono e vapor d'água. Em comparação, o óleo e os compostos de carvão possuem estruturas moleculares muito mais complexas. Elas incluem altas taxas de carbono, bem como diversos compostos de enxofre e nitrogênio, ou seja, 
não produzem uma queima tão limpa. A combustão do carvão e de óleos combustíveis industriais também produz partículas de cinza, que não queimam completamente, mas que são carregadas para a atmosfera. Já o gás natural tem uma queima limpa, por isso seu consumo pode ser encarado como uma efetiva contribuição ao controle da poluição ambiental.

A utilização do gás natural pode ajudar na manutenção da qualidade do ar e da água, principalmente quando substitui outras fontes de energia mais poluentes.

Pode ser visto na tabela 2 que a combustão do gás natural resulta em uma emissão muito menor de gases poluentes do que a combustão dos outros combustíveis fósseis como o carvão e o óleo combustível. Por esse e outros motivos, dando-se a devida importância a questão ambiental, o gás natural é considerado o combustível do século XXI.

\begin{tabular}{|c|c|c|c|}
\hline Poluente & Gás Natural & Óleo combustível & Carvão \\
\hline $\mathrm{CO}_{2}$ & 117.000 & 164.000 & 208.000 \\
\hline $\mathrm{CO}$ & 40 & 33 & 208 \\
\hline $\mathrm{NO}_{X}$ & 92 & 448 & 457 \\
\hline $\mathrm{SO}$ & 1 & 1,122 & 2.591 \\
\hline Particulados & 7 & 84 & 2.744 \\
\hline Mercúrio & 0,000 & 0,007 & 0,016 \\
\hline
\end{tabular}

Tabela 2 - Quantidade de poluentes gerados em libras/bilhão BTU por combustível fóssil. [1]

Contudo, o vazamento de gás representa um grande perigo, porque uma faísca sequer já é capaz de gerar uma explosão seguida de incêndio. O perigo é ainda maior quando o vazamento ocorre numa rede de distribuição de gás, onde há grande fluxo de gás, passando adjacente ao vazamento, que pode se tornar um combustível para um possível incêndio e/ou explosão. Além disso, existem outros riscos como a própria inalação do gás pelas pessoas próximas. Dependendo da quantidade de gás inalada pela pessoa, pode levar a tontura, a desmaio e até a óbito. Devido a esses riscos, tornou-se necessária a inspeção das redes para prevenir qualquer tipo de acidente.

Existe a dificuldade de identificar um possível vazamento de gás natural porque ele tem uma característica muito peculiar entre os combustíveis energéticos que é ser inodoro e incolor, o que impede que medidas corretivas, que impeçam esse vazamento, sejam tomadas. Em virtude da necessidade de segurança e identificação do produto, o gás natural é odorizado, ou seja, ele é misturado com substâncias que atribuem odor ao gás resultante da mistura sem interferir nas 
características energéticas. Assim, a sua presença pode ser facilmente detectável por qualquer pessoa, antes que a mistura alcance níveis potencialmente perigosos. A intensidade do odor de um gás combustível é uma sensação; sendo assim, não é uma grandeza mensurável. Porém existem procedimentos que permitem atribuir uma escala de valor ao impacto do odor percebido por uma pessoa. Para realizar a odorização, utilizam-se misturas de mercaptanas constituídas de componentes tais como o tercbutilmercaptana, o isopropilmercaptana, o N-propilmercaptana etc [1].

Um conjunto de tarefas é apresentado neste trabalho mostrando como investigar e localizar os possíveis escapamentos de gás existentes nas canalizações, que compõem as redes e ramais de distribuição de gás natural. 


\section{2. \\ Equipamentos do sistema de distribuição de gás}

Para garantir a distribuição do gás natural de forma segura, é necessária a utilização de alguns equipamentos mecânicos ao longo da rede e nos locais específicos de distribuição. Além das tubulações propriamente ditas, o conjunto de equipamentos são: válvulas, filtros e reguladores. São nesses equipamentos em que os vazamentos de gás são mais comuns. E juntamente com esses equipamentos vêm as tubulações que podem ser aéreas ou enterradas.

\section{1}

\section{Válvulas}

As válvulas podem ser subdividas em quatro tipos: válvulas de bloqueio, válvulas de regulagem e válvulas de retenção (anti-retorno). A figura 1 apresenta o exemplo de uma válvula de bloqueio.

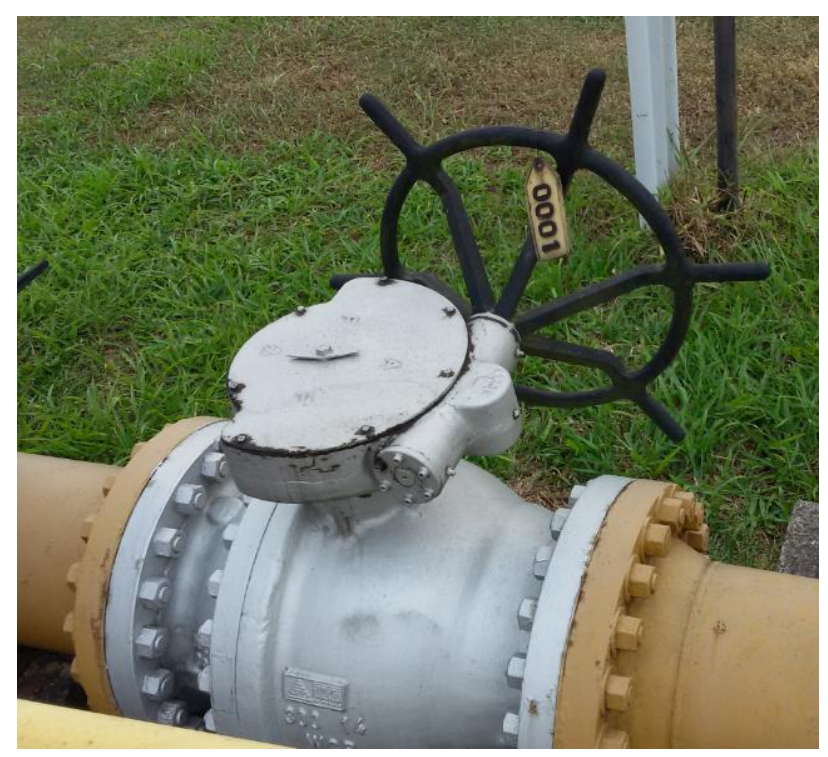

Figura 1 - Exemplo de uma válvula de bloqueio.

As válvulas de bloqueio são instaladas para interromper a passagem de gás, podendo ser manuais ou automáticas e têm como função principal nas indústrias a interrupção do fluxo de gás em situações planejadas ou emergenciais, além de possibilitar as paradas para manutenção dos equipamentos. Elas só podem ser posicionadas de duas maneiras: abertas ou fechadas. Elas permanecem na posição aberta enquanto a instalação estiver com sua pressão dentro dos limites normais de operação. Uma vez acionadas por elevação ou queda de pressão, elas 
permanecem fechadas para garantir a integridade da instalação. Atualmente, o tipo de válvula de bloqueio mais utilizada para gás natural é a do tipo esfera [1].

As válvulas de regulagem são utilizadas para controlar o fluxo de gás, podendo trabalhar em diversas posições de ajuste além da completamente aberta e da completamente fechada.

As válvulas de retenção são instaladas para evitar que o fluxo de gás ocorra no sentido oposto, por isso também são chamadas de válvulas anti-retorno. Elas não apresentam grande resistência ao escoamento quando ele ocorre no sentido correto, porém no sentido contrário as válvulas retêm o escoamento, impedindo o retorno do fluxo no sentido contrário.

As válvulas de alívio são instaladas para garantir a integridade e a segurança dos sistemas de distribuição de gás natural. Elas funcionam da seguinte maneira: quando ocorre um aumento de pressão a montante acima da pressão de segurança de uma determinada tubulação, a válvula de alívio abre e libera parte do fluxo de gás para a atmosfera com a finalidade de reduzir a pressão da instalação.

Durante a manutenção preventiva de uma válvula da rede, é verificada a manobrabilidade dela para que não haja problemas de manuseio da mesma quando for necessário que ela seja fechada por urgência devido a problemas na rede. Além disso, uma inspeção de detecção de escapamentos de gás é realizada na válvula ou na caixa subterrânea que a contenha no caso da válvula enterrada.

\section{2}

\section{Filtros}

No seu percurso desde o poço de produção até o consumidor, na sua cadeia de abastecimento, o gás natural é passível de arrastar partículas sólidas e líquidas, as quais podem ser provenientes do poço de produção ou dos compressores. Apesar de o gás natural ser o mais isento de impurezas dentre os combustíveis fósseis, existe a possibilidade da presença de resíduos de água, enxofre e dióxido de carbono mesmo com todos os cuidados que são tomados durante sua retirada e transporte. A água pode levar à formação de hidretos, e o enxofre à formação de ácidos, sendo que ambos atacarão a tubulação [1]. O dióxido de carbono pode levar à formação de ácidos em tubulações de alta pressão, causando corrosão nelas [1]. Dessa forma, 
o fluxo de gás, em atrito com a parede interna da tubulação, desprende e arrasta partículas oriundas dessa corrosão. Em linhas novas, podem ainda estar presentes limalhas metálicas, bem como respingos e carepas de solda provenientes de limpeza malfeita, e pequenas quantidades residuais de água, oriundas do teste hidrostático, que também são todos arrastados pelo fluxo do gás.

Algumas impurezas podem provocar entupimento ou interferir na vedação de alguns equipamentos de segurança, fazendo com que estes venham a falhar no momento em que deveriam funcionar e, com isso, provocar acidentes diretos ou indiretos [1].

Diante destes problemas, a filtragem de gases tem apresentado importância crescente nas aplicações do gás natural nas indústrias, em virtude das exigências, cada vez maiores, de grau de limpeza do gás, dada a comprovação de vantagens cada vez mais contundentes, além de maior segurança à rede. A remoção de impurezas contidas no gás traduz-se em economia devido a redução dos custos de manutenção na substituição de componentes internos que se desgastam mais rapidamente pela erosão causada por tais impurezas que podem, ainda, causar problemas de travamento que exigirão a substituição completa do equipamento. A figura 2 apresenta alguns filtros.

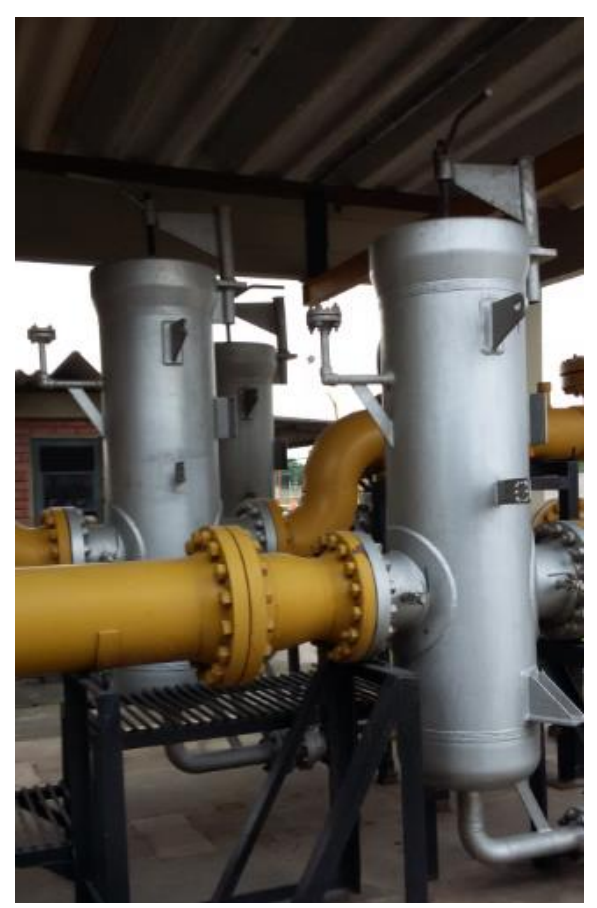

Figura 2 - Exemplos de filtros. 
Os filtros consistem no uso de um meio filtrante para separar as impurezas do fluido a ser transportado (gás natural). A manutenção preventiva de um filtro é realizada da seguinte maneira: fecha-se a válvula de entrada para interromper o escoamento, abre-se o filtro para verificar a quantidade de pó, e se a quantidade de pó for muito elevada, troca-se o filtro. Também é verificado se há um possível vazamento de gás pelo filtro.

\section{3}

\section{Reguladores}

O regulador é um equipamento que tem como objetivo estabilizar a pressão de saída, de onde é instalado o gás, independentemente de qualquer variação da pressão de entrada e da vazão que por ele escoa. Essa pressão de saída é mantida relativamente constante variando dentro de uma faixa de tolerância. Os reguladores são também conhecidos como válvulas reguladoras de pressão ou redutoras de pressão, e são auto-operados, ou seja, utilizam a própria energia do gás para controlar a pressão [1]. Os reguladores podem ser de dois tipos: ação direta ou pilotado.

O regulador de ação direta possui um sistema de atuação onde é possível controlar a pressão de saída do gás. Esse sistema possui uma mola (ajustada para uma determinada pressão de saída) que força o diafragma para baixo deixando o orifício de restrição (passagem por onde o gás passa) totalmente aberto através do regulador. Quando o fluxo de gás entrar no regulador, ele vai sair pelo orifício de restrição formando uma pressão de saída [1]. Esta pressão, inicialmente elevada, atuará na parte inferior do diafragma, agindo contra a ação da mola. O orifício de restrição tenderá a fechar, até o ponto em que a pressão, após diminuir, se estabilize no valor desejado, ou seja, até o ponto em que a pressão de saída, na parte inferior do diafragma, se equilibre com a força da mola, aplicada na parte superior do diafragma [1].

Um aumento na pressão de saída forçará o diafragma para cima, fechando mais o orifício. Dessa forma, passará menos gás e a pressão diminuirá até o limite desejado. Enquanto que uma diminuição na pressão de saída fará com que a mola force o diafragma para baixo, abrindo mais o orifício. Dessa forma, passará mais gás e a pressão aumentará até o limite desejado [1]. 
Por outro lado, se houver um aumento de pressão de entrada, maior quantidade de gás passará pelo orifício, aumentando a pressão de saída. Esta atuará no diafragma, fechando o orifício até o ponto desejado. Se houver uma queda na pressão de entrada, menos gás passará para a válvula. A pressão de saída cairá e a força da mola fará abrir o orifício, aumentando o fluxo de gás e restabelecendo o equilíbrio [1]. A figura 3 apresenta o desenho esquemático de um regulador de ação direta.

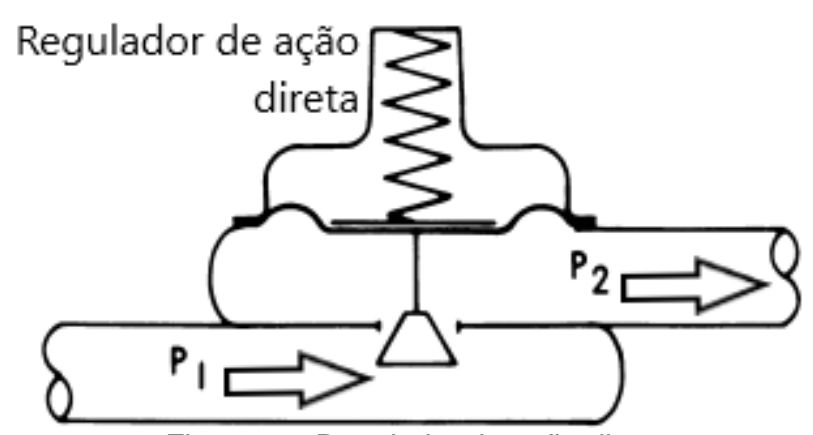

Figura 3 - Regulador de ação direta.

O regulador pilotado utiliza, além do regulador inerente à aplicação propriamente dita, um regulador de carga, doravante denominado de piloto, cuja função é de melhorar a precisão do controle da pressão regulada. O ajuste é realizado pela mola do regulador piloto e não do principal. A alimentação (pressão de carga) é obtida por meio da utilização da própria pressão a montante do regulador. Para esse tipo de regulador pilotado, existe um escape constante da pressão de carga para a atmosfera [1]. Quando a vazão começa a aumentar, a pressão a jusante do regulador começa a diminuir e ao diminuir P2 (presente na figura 4), a pressão de carga desloca o diafragma para baixo e o abre para compensar essa maior demanda. Ao empurrar o diafragma do regulador principal para baixo, o volume ocupado pela pressão de carga aumenta. Dessa maneira a pressão de carga diminui, o que faz o piloto empurrar seu diafragma para baixo, abrindo sua passagem, permitindo que a pressão de carga se restabeleça no seu ponto de ajuste e, consequentemente, abrindo ainda um pouco mais o regulador principal.

Quando há um aumento na pressão de saída, o volume ocupado pela pressão de carga é menor aumentando a pressão de carga, sendo esse excesso de pressão aliviado para a atmosfera [1]. A figura 4 apresenta um desenho esquemático de um regulador pilotado. 


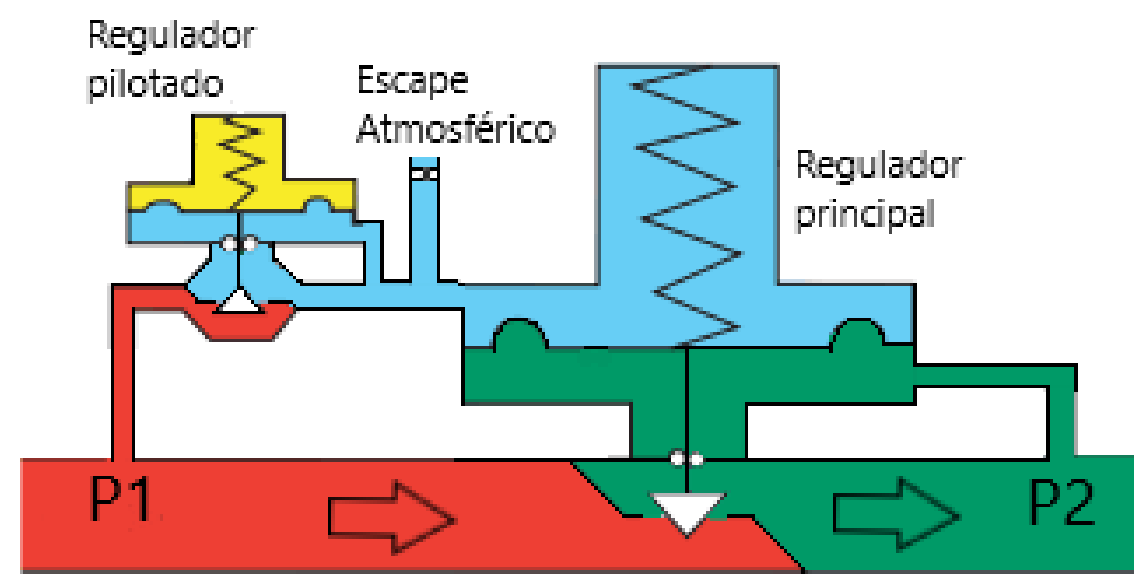

Figura 4 - Regulador pilotado. [1]

Nota-se que nessa configuração de regulador a pressão de carga varia muito pouco com o deslocamento do conjunto disco/diafragma, ao contrário do que ocorre com o regulador de ação direta. Dessa forma, diminui consideravelmente a imprecisão no controle devido aos desvios provocados pelos efeitos da mola e do diafragma. $\mathrm{O}$ desvio de controle de pressão causado pelo diafragma é minimizado por causa do fato de o diafragma estar submetido a pressão em ambas as faces, o que faz com que, nele, praticamente não ocorram deformações. Pode-se concluir que os reguladores pilotados apresentam maior precisão quando comparados com os reguladores de ação direta, entretanto possuem custo maior por terem maior quantidade de componentes.

\section{4}

Tubulações aéreas e enterradas

As tubulações são as responsáveis por direcionar o fluxo de gás garantindo sua distribuição aos clientes. Elas podem ser aéreas ou enterradas. Na maioria das vezes são enterradas.

As tubulações aéreas devem ser sempre suportadas. Os suportes da tubulação são dispositivos destinados a suportar os pesos e demais esforços exercidos pela tubulação, ou sobre ela, transmitindo esses esforços diretamente ao solo ou às estruturas vizinhas [1]. A inspeção para detectar escapamentos de gás é muito mais simples na tubulação aérea porque o gás se dispersa na atmosfera permitindo uma inspeção sem interferência de um acúmulo de gás. Pode ser visto na figura 5 exemplos de tubulações aéreas. 


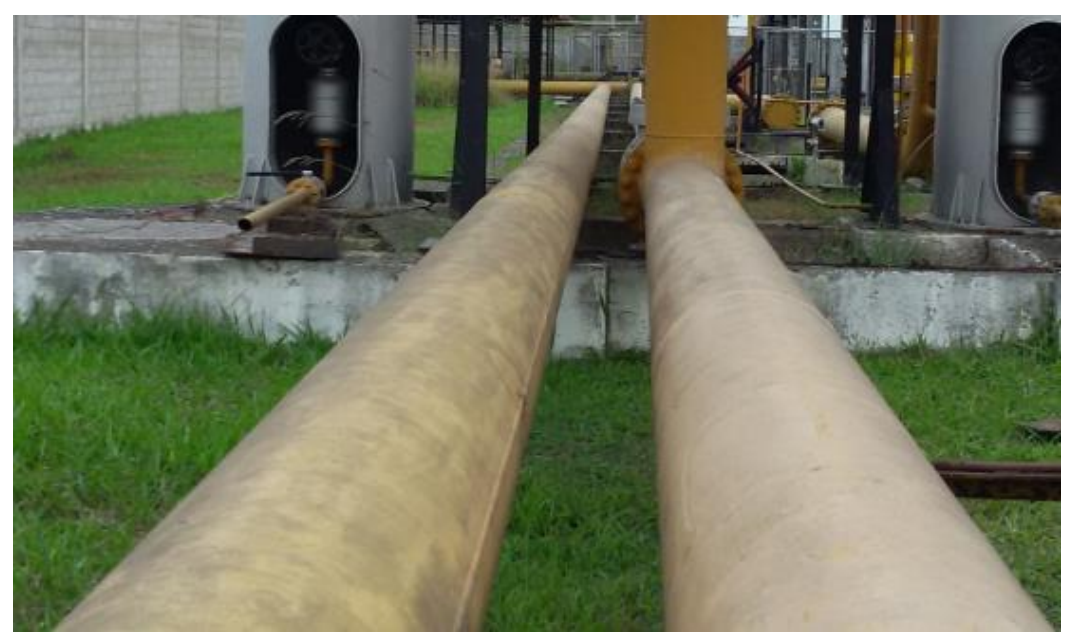

Figura 5 - Tubulações aéreas.

As tubulações enterradas não devem ficar sujeitas a possíveis esforços provenientes de construções. As valas para colocação dos tubos devem ter seção retangular, a menos que a consistência do terreno não o permita. A largura da vala deve ser a mínima possível, geralmente bastando medir 30 centímetros a mais que o diâmetro externo dos tubos [1]. Quando os tubos forem assentados diretamente no solo, o fundo da vala deverá receber uma camada de, no mínimo, 100 milímetros de terra limpa, bem compactada para servir de base à tubulação [1]. O reaterro da vala, até 200 milímetros acima da geratriz superior do tubo, deve ser efetuado com material selecionado, isento de pedras ou outros materiais estranhos, e bem compactado ao lado e acima dos tubos [1]. O reaterro da vala deve ser completado com material de densidade aproximadamente igual à do terreno original [1]. É prudente colocar a proteção catódica nas tubulações de aço enterradas, que é uma técnica de combate à corrosão. As redes de tubos de polietileno vêm sendo muito usadas ultimamente, em virtude da queda de preço. O polietileno é um material muito fácil para se trabalhar por causa de sua flexibilidade. 


\section{3. \\ Parâmetros Normativos}

Para investigar e localizar as possíveis fugas existentes nas canalizações que compõem as redes e ramais de distribuição de gás, utiliza-se a norma NT-200BRA Parte 4 da Agenersa [3]. Esta norma apresenta critérios e procedimentos técnicos de distribuição e manutenção de ramais e redes e define a frequência que devem ser feitas as detecções de acordo com alguns critérios que serão explicados mais a frente. Ela também classifica os níveis de fuga e seus respectivos prazos de resolução, além de definir se uma rede deve ou não ser substituída.

\section{1}

\section{Frequência}

Um programa sistemático de controle de estanqueidade da rede foi elaborado de acordo com a NT-200-BRA Parte 4 da Agenersa [3]. Foram separados três tipos de rede para que se pudesse definir a frequência que devem ser feitas as detecções. Na tabela 3 podem ser vistos os três tipos de rede, cada um com sua frequência de detecção.

\begin{tabular}{|c|c|}
\hline SITUAÇÃO & FREQUÊNCIA \\
\hline A MPO for menor ou igual a quatro bar & Uma vez a cada dois anos \\
\hline A MPO for maior que quatro bar fora de núcleos urbanos & Uma vez a cada quatro anos \\
\hline A MPO for maior que quatro bar dentro de núcleos urbanos & Uma vez a cada dois anos \\
\hline \multicolumn{2}{|c|}{ Tabela 3 - Frequências que devem ser realizadas as detecções. }
\end{tabular}

Além das situações descritas acima, deve se levar em conta algumas situações especiais. São elas:

- Redes que apresentam um índice de fugas maior que 3 fugas por quilômetro de duto.

- Redes de média e baixa pressão compostas por ferro fundido.

Nessas situações, a detecção de fuga deve ser realizada uma vez por ano. No entanto, se forem detectados comportamentos isolados que precisam de um estudo mais detalhado, a área de manutenção responsável pode determinar a frequência de pesquisa que deva ser aplicada no setor afetado. 


\section{2}

\section{Classificação dos níveis de fuga}

Durante a operação de detecção de escapamentos, as fugas de gás encontradas devem ser classificadas de acordo com a NT-200-BRA Parte 4 da Agenersa [3]. As fugas são classificadas em três níveis.

As fugas de nível 1 são aquelas emergenciais, onde é necessário a interdição do local de acordo com a NT-200-BRA Parte 4 da Agenersa [3] para que a fuga seja tratada imediatamente. Elas se caracterizam dessa maneira devido a sua localização ou intensidade (vazamento igual ou acima de 90\% em volume de gás), seja pela possibilidade real de intoxicação, asfixia, incêndio ou explosão perto de escolas, casas ou condomínios, ou pela possibilidade de o gás penetrar nos edifícios, coletores, caixas subterrâneas, equipamentos eletrônicos ou automáticos.

As fugas de nível 2 são aquelas que não oferecem riscos potenciais, por não apresentarem os fatores ou circunstâncias expostas para o nível 1. Entretanto a perda de gás em uma fuga de nível 2 é considerável, atingindo valores entre $20 \%$ e $89 \%$ em volume ao medir o escapamento.

As fugas de nível 3 não apresentam gravidade, porém é necessário o acompanhamento para que elas não evoluam para o nível 2, e posteriormente para o nível 1. Seus valores de fuga atingem no máximo $19 \%$ em volume.

\section{3}

\section{Prazos de resolução das fugas}

A fuga deve ser eliminada através do reparo ou da substituição do ramal ou do trecho onde elas estão presentes de acordo com a NT-200-BRA Parte 4 da Agenersa [3]. Cada nível de fuga tem um prazo de resolução específico.

As fugas de nível 1 são prioridade e precisam ser eliminadas de imediato para evitar qualquer tipo de acidente. A equipe que detecta esse tipo de fuga não deve abandonar o local da ocorrência enquanto a equipe de emergência não chegar ao local para eliminar o vazamento.

As fugas de nível 2 têm tempos máximos de resolução dependendo da maneira que serão removidas. Para reparo no vazamento, o tempo máximo de ação é de três meses. E para substituição do trecho com a fuga, o tempo máximo de ação é de seis meses. 
As fugas de nível 3 precisam de um estudo de caso para cada uma. No caso de ela ser detectada, deve haver uma nova avaliação com tempo máximo de ação de seis meses. Após a nova avaliação, a fuga é classificada novamente em um dos três níveis ou não havendo a fuga, deve-se classificá-la como "sem resultado". Se ela evoluir para nível 1 , deve ser eliminada imediatamente pela equipe de emergência. Se ela evoluir para nível 2, deve ser removida conforme o prazo de resolução (reparo ou substituição do trecho). Se ela continuar sendo classificada como nível 3, deve ser realizada uma reavaliação com tempo máximo de ação de três meses, e persistindo o nível 3 pela terceira vez seguida, a fuga deve começar a ser tratada como nível 2.

Através dessa norma de inspeção, é possível manter o controle de estanqueidade de toda a rede, evitando acidentes envolvendo o gás natural e minimizando as perdas econômicas. 


\section{4. \\ Tecnologia aplicada}

Para realizar a detecção de escapamentos de gás em válvulas, ramais e redes, utiliza-se sensores de última geração, como: tonalidade térmica, semicondutores, lazer, ionização de chamas, condutibilidade térmica, combustão catalítica e raio infravermelho.

A leitura direta de aparelhos e/ou instrumentos pode determinar a concentração de certos gases no ambiente. As informações necessárias podem ser lidas diretamente em um mostrador ou indicador do instrumento após as análises e as amostras realizadas com o equipamento que carrega o instrumento. $\mathrm{O}$ instrumento ideal para a leitura direta em campo deverá ter a capacidade de fornecer no indicador a taxa de concentração de cada uma das substâncias desejadas que estejam sendo analisadas.

O equipamento portátil de leitura direta, medição e detecção de gases, que a equipe em campo utiliza, tem um sistema de medição por sistema eletrônico muito preciso e moderno que funciona através de um chip e um analisador [4]. Eles são utilizados para quantificar a medição dos gases e fornecer a indicação digital do resultado para a leitura do técnico em campo.

\section{1}

\section{Tipos de sensores utilizados no serviço de detecção}

FID (PORTAFID) - Ionização de chama - Por aspersão mecânica da mistura gás/ar e processamento por câmara de ionização de chamas alimentada por mistura padrão $\mathrm{N} 2 / \mathrm{H} 2$, gerando sinais elétricos para decodificação e indicação dos valores no painel.

Medidor LIE (Explosímetro) - Combustão catalítica - Por aspersão não mecânica da mistura gás/ar e processamento por célula eletroquímica, efetuando a combustão catalítica e a geração de sinais elétricos para decodificação e indicação dos valores no painel.

Medidor de volume (Gasophon) - Propagação de som na mistura - Por aspersão mecânica da mistura gás/ar e processamento por propagação do som na 
mistura, calculando o grau de resistência à propagação e gerando sinais elétricos para decodificação e indicação no painel.

Medidor de volume (Extec II) - Condutibilidade térmica - Por aspersão mecânica da mistura gás/ar e processamento por condução do calor na mistura, calculando o grau de transferência térmica e gerando sinais elétricos para decodificação e indicação no painel.

Medidor de volume (Metrex II) - Semicondutor - Por aspersão mecânica da mistura gás/ar e processamento por condução elétrica da mistura, calculando o grau de transferência elétrica e gerando sinais para decodificação e indicação no painel.

Medidor de volume (GM 3) - Tonalidade térmica - Por aspersão mecânica da mistura gás/ar e processamento por troca de calor na resistência, calculando o grau de troca de calor e gerando uma variação elétrica convertida em sinais para decodificação e indicação no painel.

Medidor de infravermelho (Protheo IR) - Raios infravermelhos - Por aspersão mecânica da mistura gás/ar e processamento por interferência ótica na célula de referência, calculando o grau de interferência molecular somente do metano, convertida em sinais para decodificação e indicação no painel.

\section{2 \\ Calibração}

Para que haja confiabilidade nos serviços de detecção de escapamentos, é fundamental que os equipamentos utilizados em campo estejam calibrados. Para verificar a calibração do EX-TEC HS 680 da Sewerin [5], é necessário seguir alguns passos:

- Aguardar o tempo necessário para aquecer o filamento do equipamento após ligá-lo e ajustar o zero do equipamento em uma sala livre de gases e vapores combustíveis.

- Verificar o estado das baterias depois de pressionar o botão de teste.

- São injetados 10 PPM (partes por milhão) de $\mathrm{CH}_{4}$ (Gás Metano) nos equipamentos com o objetivo de comprovar a sua precisão. 
Se o equipamento apresentar a resposta esperada, ele já está apto para ser utilizado nos serviços demandados pela empresa. Porém, se o equipamento não apresentar a resposta esperada com o filamento em perfeito estado, o equipamento deverá passar por um novo processo de calibração para, em caso de aprovação, poder ser utilizado novamente nos serviços de detecção de fugas. A figura 6 apresenta os acessórios adicionais utilizados para auxiliar na detecção.

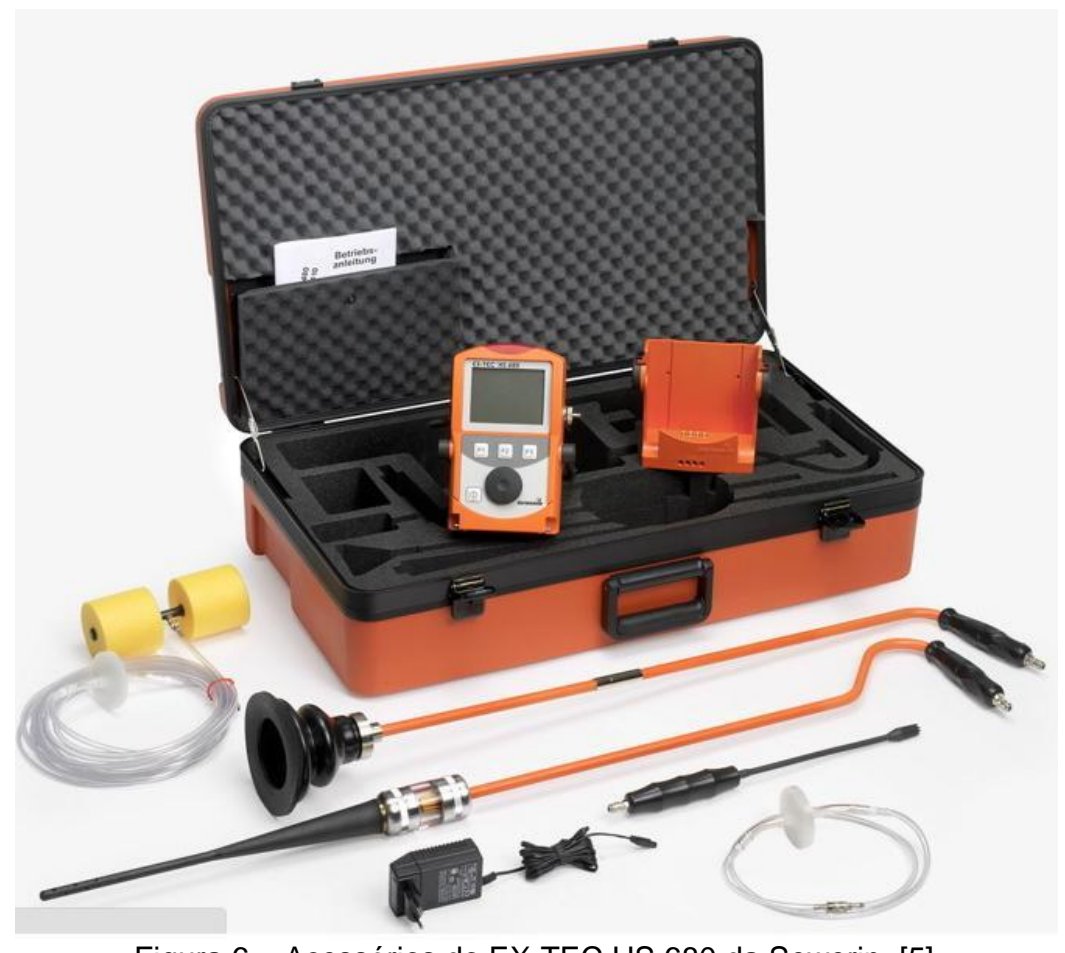

Figura 6 - Acessórios do EX-TEC HS 680 da Sewerin. [5]

Essa tecnologia assegura total segurança e qualidade no desenvolvimento das atividades de detecção de escapamentos, promovendo confiança e a precisão necessária aos serviços. 


\section{5. \\ Equipamentos e acessórios}

Como visto anteriormente, o gás natural tem concentração de 89,0\% de metano em sua composição. A partir dessa característica, é utilizado o equipamento de leitura direta nomeado de EX-TEC HS 680 da Sewerin [5] que é capaz de detectar metano na atmosfera. Junto com esse equipamento, é necessária uma sonda que passa rente à superfície, seja na terra, na calçada, na pista e em qualquer outro tipo de pavimento, onde há rede de distribuição de gás natural. Cada sonda é apropriada a um tipo de piso diferente.

O EX-TEC HS 680 é alimentado eletricamente com pilhas alcalinas e opera na temperatura de $0^{\circ} \mathrm{C}$ a $40^{\circ} \mathrm{C}$ [4]. Ele funciona a partir da combinação da reação química, da leitura óptica e dos sistemas eletrônicos. O chip presente no leitor óptico pode ser utilizado durante dois anos e permite a realização de até dez medições. O código de barras fornece os parâmetros de análise, como faixa de concentração da medição, fluxo de medição e identificação do produto a ser analisado, e estabelece a comunicação entre o chip e o analisador [4]. Esse código de barras é específico para cada reagente, no caso o metano (é opcional para propano e butano), que vem impresso em cada chip.

Após ligar o instrumento, é necessário seguir as instruções que aparecem no visor dele. Dessa maneira, a utilização do equipamento fica bem simples faltando apenas inserir o chip e mover a placa seletora. A partir disso, começa-se a passar a sonda, que é ligada ao instrumento, por cima da superfície, onde tenha tubulação, para começar a leitura e a detecção de escapamentos. A amplitude máxima de detecção é de um metro e meio. No fim do procedimento, o EX-TEC HS 680 mostra a concentração em PPM (parte por milhão) do metano no trecho medido. Ele também mostra o percentual em volume do metano presente na mistura gás/ar absorvida para análise, basta apenas trocar a opção do painel. A figura 7 apresenta o Sensor EX-TEC HS 680 da Sewerin. [5] 


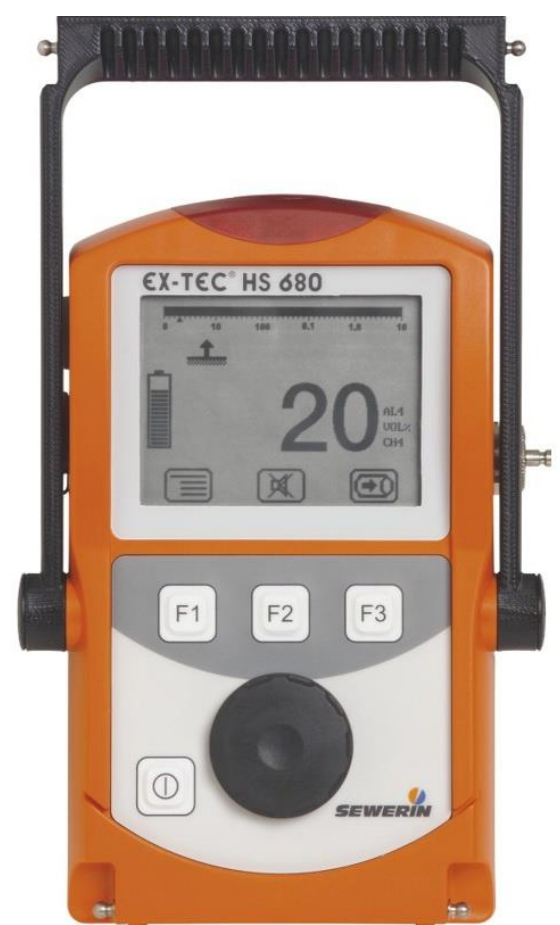

Figura 7 - Sensor EX-TEC HS 680 da Sewerin. [5]

É possível armazenar informações como horário, data, substância analisada e concentração obtida. Os dados armazenados na memória do equipamento podem ser lidos e apagados, sempre que se queira.

O EX-TEC HS 680 sozinho não faria nenhuma leitura porque ele precisa de seus acessórios para funcionar corretamente. Na lateral dele tem um pequeno tubo de orifício que é o responsável por absorver o ar da atmosfera, para facilitar a medição em locais muito altos ou no chão, é inserida uma sonda (um tubo de plástico), que tem a função de estender o comprimento de aspiração e direcionar o ar do ambiente ao equipamento portátil para leitura direta. Com isso, pode-se ver no indicador a quantidade de gás metano presente no ar aspirado pela sonda.

\section{1 \\ Sonda}

A sonda é um acessório ligado ao EX-TEC HS 680 com a função de ajudar no alcance de aspiração do equipamento e filtrar os elementos indesejáveis que estão presentes nas calçadas, nos asfaltos da cidade e nas terras em zonas rurais. Dessa forma, esses elementos ficam presos nos filtros e não interferem na leitura do EX-TEC HS 680.

São utilizados três filtros no total: dois na sonda e um no próprio EX-TEC HS 680. 
O primeiro filtro é a primeira barreira contra as impurezas encontradas no ar e no ambiente. Ele está praticamente em contato direto com o solo e/ou asfalto. Em dias de chuva, a atividade de detecção se torna impossível de acontecer porque a água da chuva presente no chão entra no primeiro filtro e o entope. Após isso, o equipamento torna-se inútil, já que não consegue mais absorver o ar do ambiente. Além disso, os asfaltos e pisos molhados impedem o gás metano (gás natural) de subir até a superfície, por isso mesmo que esteja ocorrendo algum vazamento de gás, ele não pode ser detectado pelos aparelhos nessas condições. O primeiro filtro pode ser visto na figura 8 .

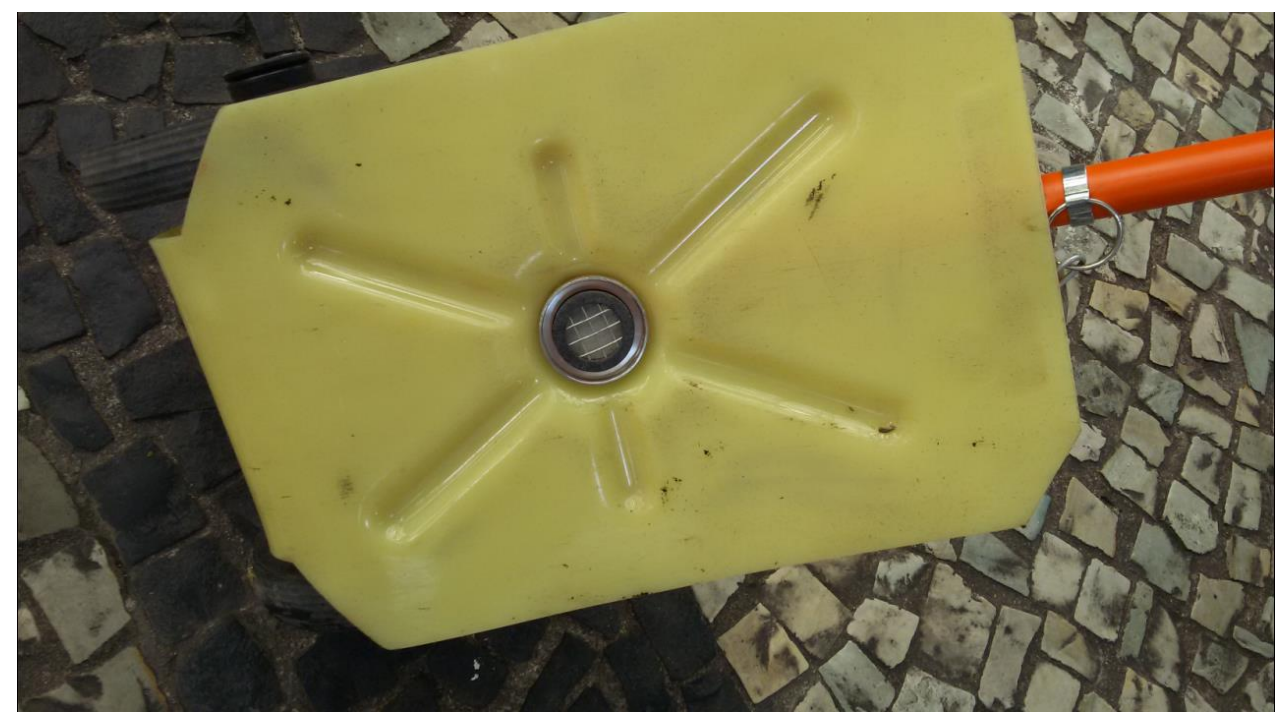

Figura 8 - Primeiro filtro.

O segundo filtro, que pode ser visto na figura 9, se encarrega de impedir a passagem dos detritos menores que são capazes de passar pelo primeiro filtro. 


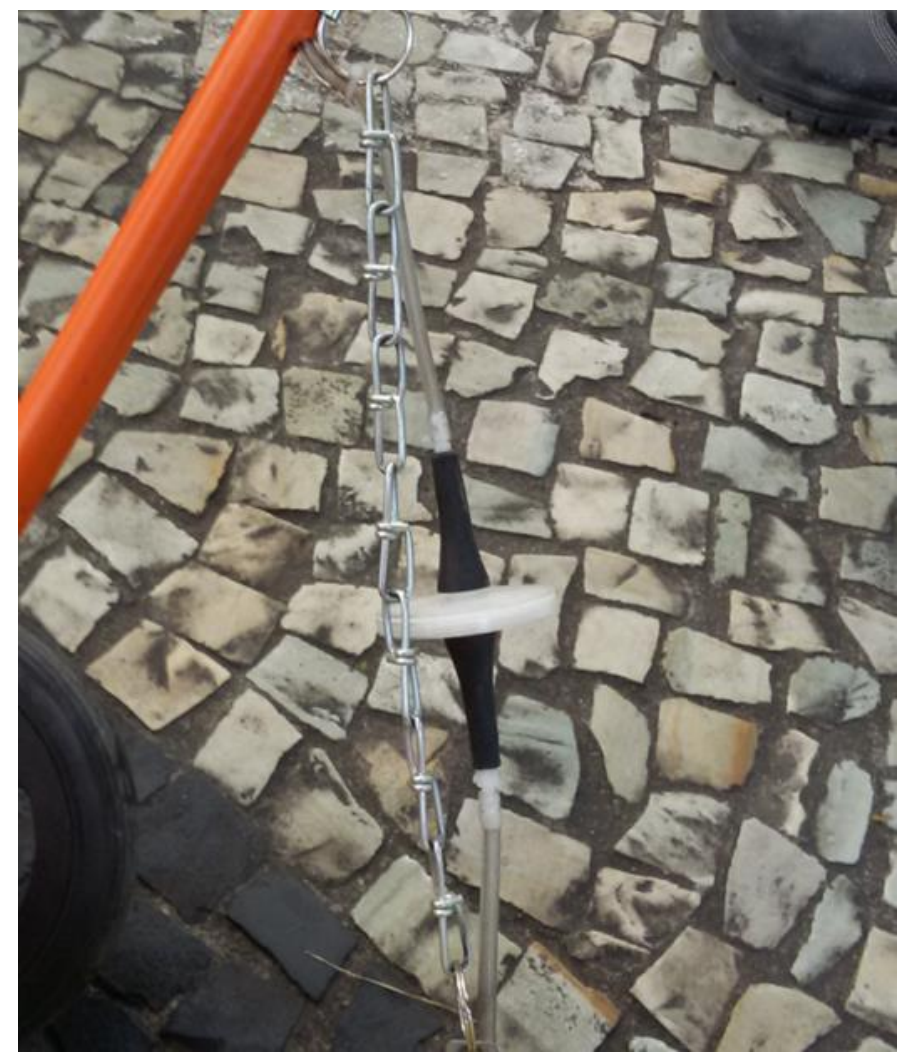

Figura 9 - Segundo filtro.

E o terceiro filtro que fica dentro do EX-TEC HS 680 separa a mistura gás/ar das impurezas ainda restantes que puderam atravessar os primeiros dois filtros. Dessa forma a mistura gás/ar pode ser analisada pelo aparelho sem maiores interferências e posteriormente indicar no leitor dele o resultado da amostra. A figura 10 indica o local onde fica o terceiro filtro no EX-TEC HS 680.

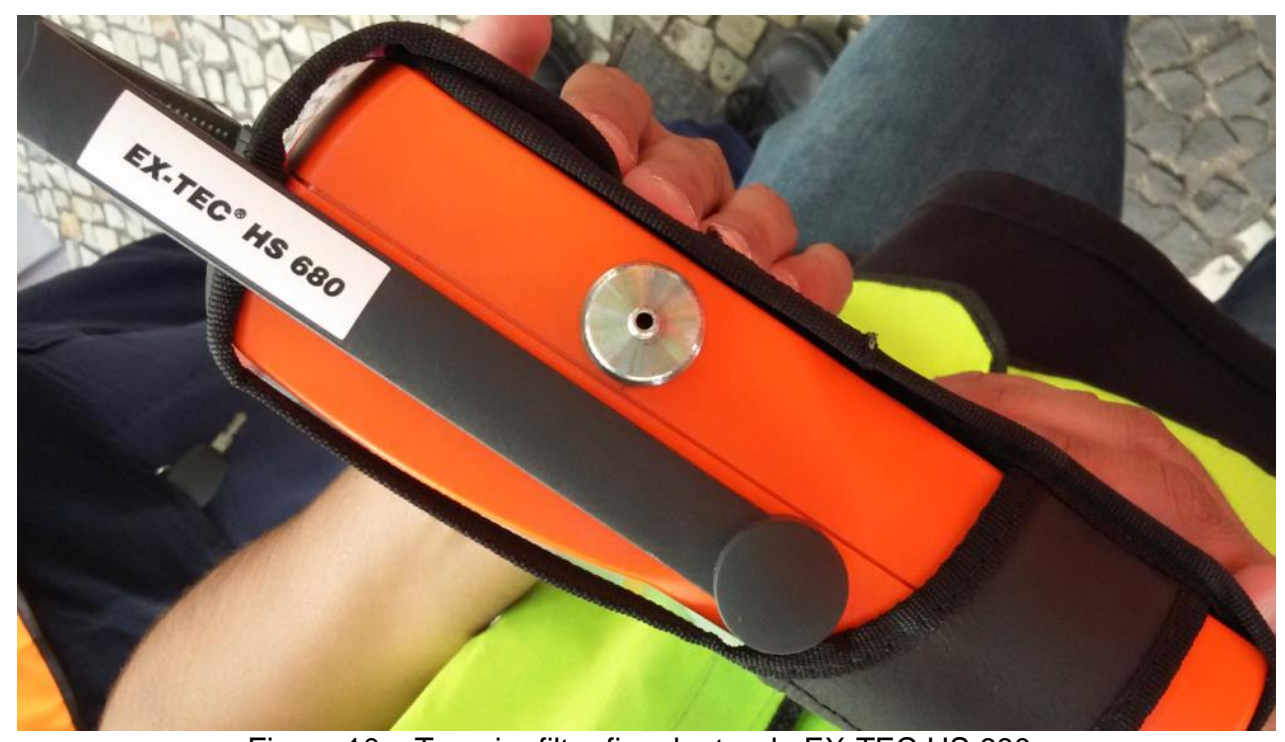

Figura 10 - Terceiro filtro fica dentro do EX-TEC HS 680.

\section{2}




\section{Bomba de sucção}

Quando há uma grande detecção de metano medido através do EX-TEC HS 680 durante o trabalho, é utilizada uma bomba de sucção para drenar o acúmulo de gás liberado pelo vazamento do gasoduto abaixo da superfície. A bomba de sucção trabalha através da diferença de pressão, reduzindo a pressão na bomba para que a pressão atmosférica, que será maior, leve o gás até a bomba para ser expelido. A figura 11 apresenta uma bomba de sucção.

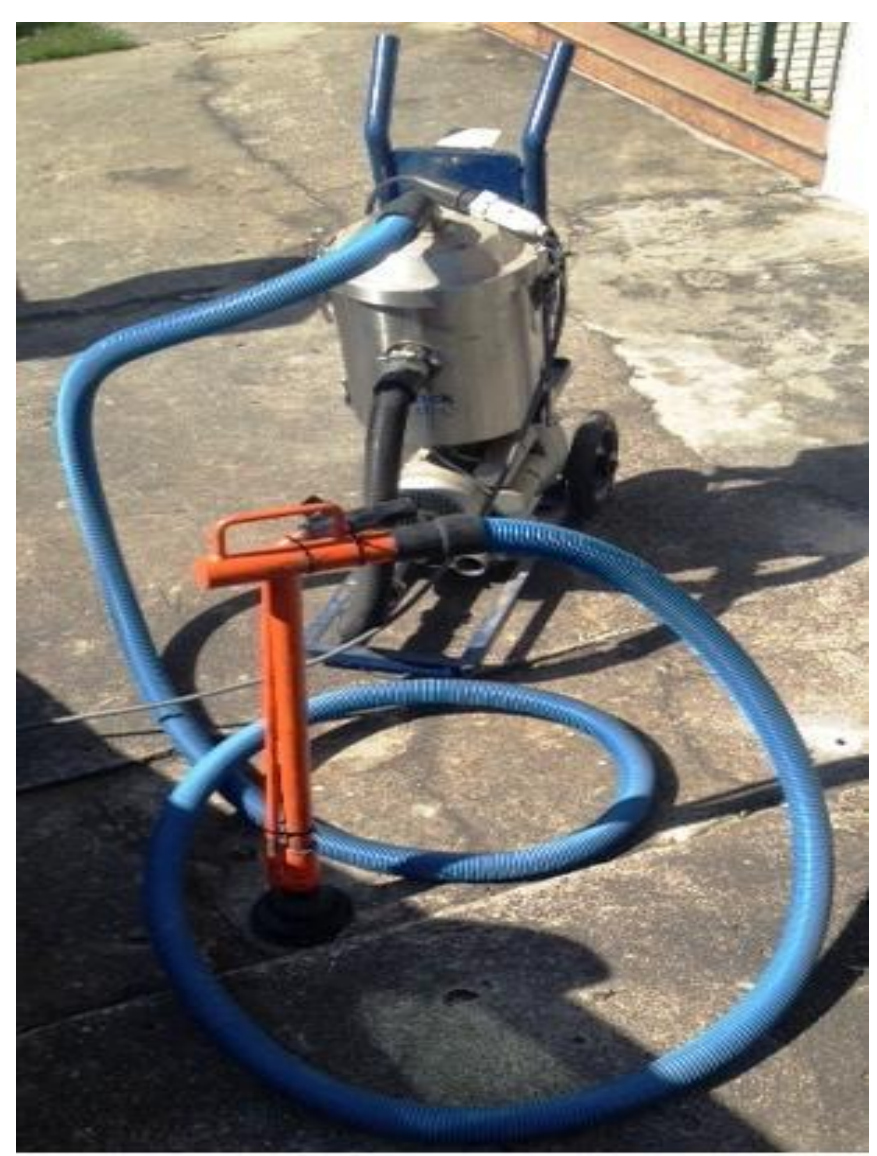

Figura 11 - Bomba de sucção.

Mesmo após o reparo da fuga que existia na tubulação, os gases que escaparam continuam presos abaixo da superfície. A bomba de sucção elimina esses gases para que se possa fazer uma nova medição de detecção com o objetivo de garantir que o vazamento de gás foi eliminado por completo. 


\section{3 \\ Equipamentos de proteção individual}

Para realizar os serviços em locais que possam imprimir algum tipo de risco físico para o trabalhador, é obrigatória a utilização dos equipamentos de proteção individual (EPI) segundo a Norma Regulamentadora 6 [6]. As funções desses equipamentos é evitar possíveis acidentes de trabalho e minimizar as consequências e os danos provocados à saúde física dos funcionários caso ocorra algum tipo de sinistro. Foi elaborado um estudo dos riscos ocupacionais envolvidos nas atividades de detecção, definindo que é obrigatório o uso dos seguintes equipamentos: capacete, botas, colete, abafador e óculos de impacto.

Os capacetes de segurança são responsáveis pela proteção da cabeça contra impactos e ferimentos causados pela queda de materiais. Dessa maneira, um impacto que provocaria uma lesão séria na cabeça do trabalhador com subsequentes sequelas pode ser protegido. Pode ser visto na figura 12 um exemplo de um capacete de segurança.

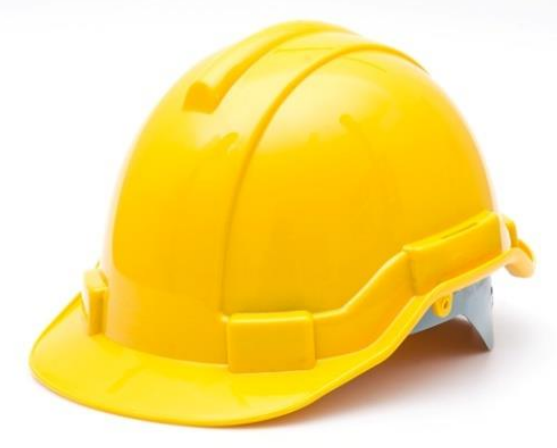

Figura 12 - Capacete.

Em ambientes com grande risco de acidentes de trabalho, a utilização das botas se torna ainda mais importante, para evitar cortes, queimaduras, aparecimento de bolhas e dores devido a extensos períodos de movimentação. Seguem as botas na figura 13. 


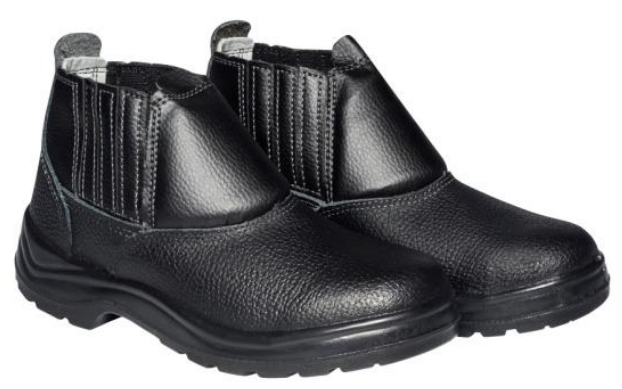

Figura 13 - Botas.

O serviço de detecção de fugas é realizado nas calçadas de ruas e próximo às vias de tráfego de alta velocidade, por isso se tornou obrigatória a utilização de coletes retrorreflexivos pelos trabalhadores para que esses fossem visualizados de longe pelos motoristas. Esses coletes podem ser vistos na figura 14.
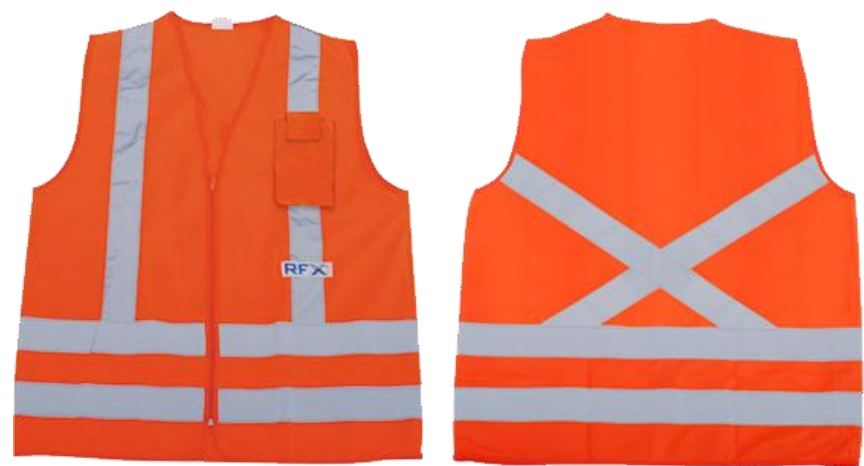

Figura 14 - Colete retrorreflexivo (frente e verso).

O protetor auditivo é a solução mais simples e eficiente de atenuar o som e permitir a proteção do trabalhador contra os altos níveis de ruído e a perda auditiva. Os abafadores contêm uma espuma na parte interna da cavidade das conchas que protegem os ouvidos. Já os protetores de inserção são feitos de silicone e se adéquam ao ouvido de qualquer trabalhador, ele é comprimido e inserido no ouvido da pessoa e se molda e expande dentro do ouvido fornecendo proteção ao indivíduo. Um abafador e um protetor de inserção podem ser vistos na figura 15.

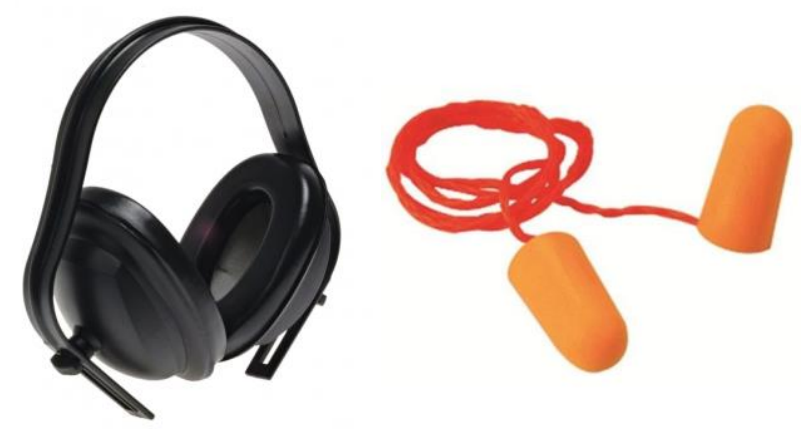

Figura 15 - Abafador e protetor de inserção. 
Para a proteção adequada dos olhos nas horas de trabalho em locais perigosos e com possibilidade de acidentes graves, são disponibilizados obrigatoriamente os óculos de impacto para os funcionários. Eles podem ser vistos na figura 16.

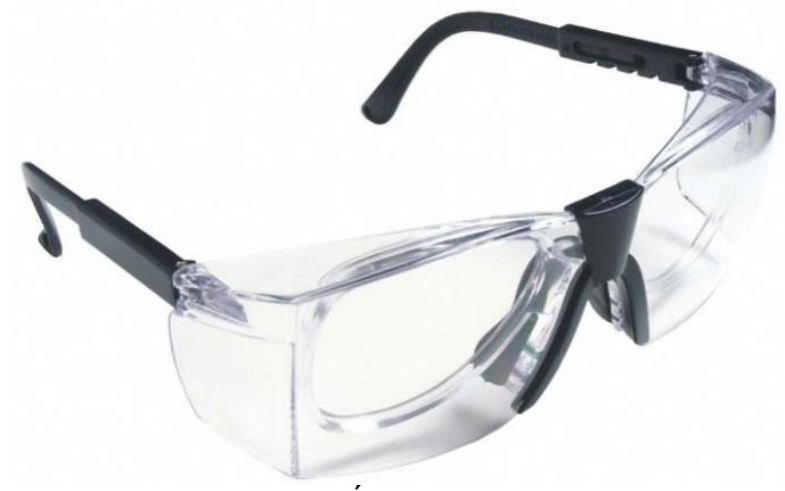

Figura 16 - Óculos de impacto.

Com a utilização de todos esses equipamentos de proteção individual, foi permitido o acompanhamento do serviço de detecção de fugas. 
6.

\section{Procedimento prático}

O procedimento prático deste trabalho foi feito em redes de baixa pressão porque são as mais propensas a ocorrer vazamentos para colocar em prática o funcionamento dos equipamentos de detecção de vazamentos. Na figura 17 pode ser visto uma equipe realizando o serviço de detecção.

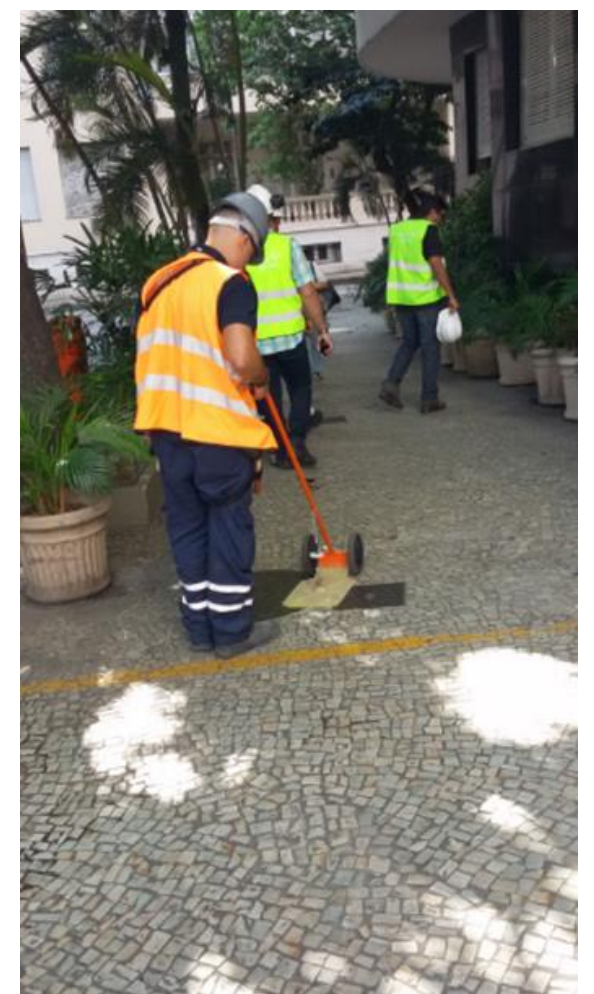

Figura 17 - Equipe realizando o serviço de detecção de escapamentos. 
Para localizar as tubulações que estão enterradas nas ruas, foi necessário observar pela planta de um aplicativo cartográfico, que indica a localização das redes. Na figura 18 é possível visualizar a planta que mostra um exemplo de um trecho, onde há tanto rede de ferro fundido de um lado quanto rede de polietileno do outro lado.

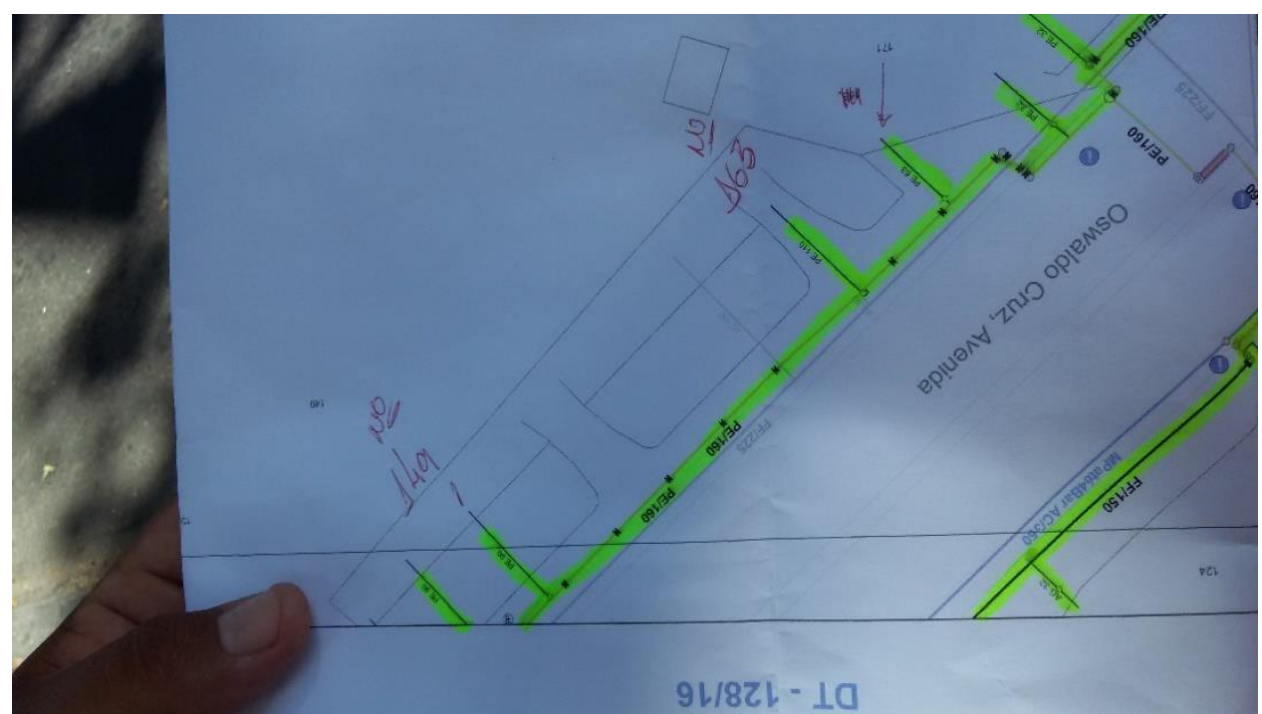

Figura 18 - Planta impressa de um aplicativo cartográfico que auxilia na localização das tubulações.

Com o auxílio da planta o serviço de detecção foi realizado passando por cima das redes utilizando os equipamentos já mencionados como o EX-TEC HS 680 da Sewerin [5], as sondas e os três filtros. O EX-TEC HS 680, que detecta metano na atmosfera, tem um leitor de tela no qual aparece a quantidade de metano em PPM (partes por milhão). Caso a quantidade de metano ultrapasse 60 partes por milhão, o detector liga um alarme sonoro caracterizando um vazamento e a partir daí o trabalhador responsável registra na planta a localização exata da medição que ultrapassou essa quantidade de metano. Na figura 19 o medidor mostra uma leitura de 5 partes por milhão de metano. 


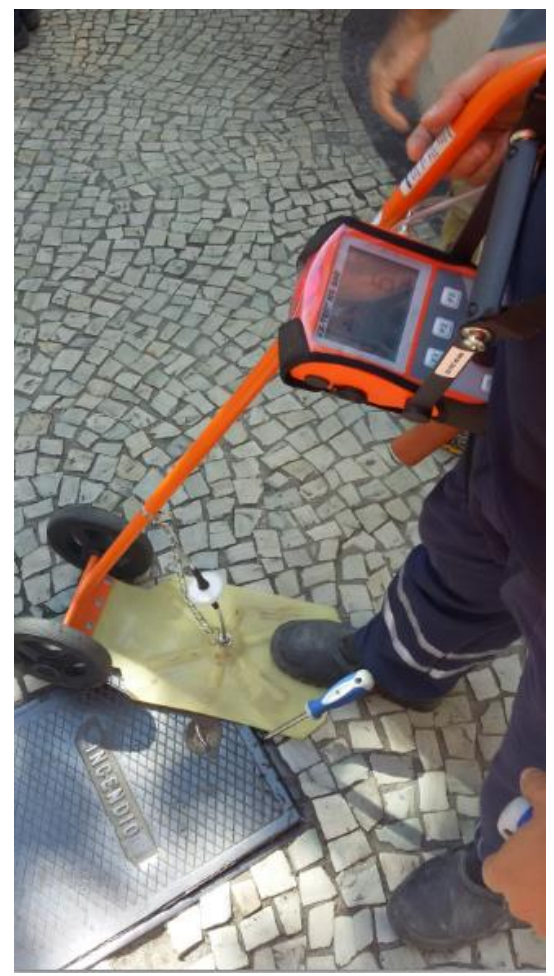

Figura 19 - Medidor mostrando uma leitura de 5 partes por milhão de metano.

Em certos lugares durante o percurso foi possível identificar vazamentos de gás natural com a ajuda dos equipamentos. Na figura 20 segue um exemplo de uma medição de gás natural acima da normalidade com 750 partes por milhão (o normal é abaixo de 60 partes por milhão).

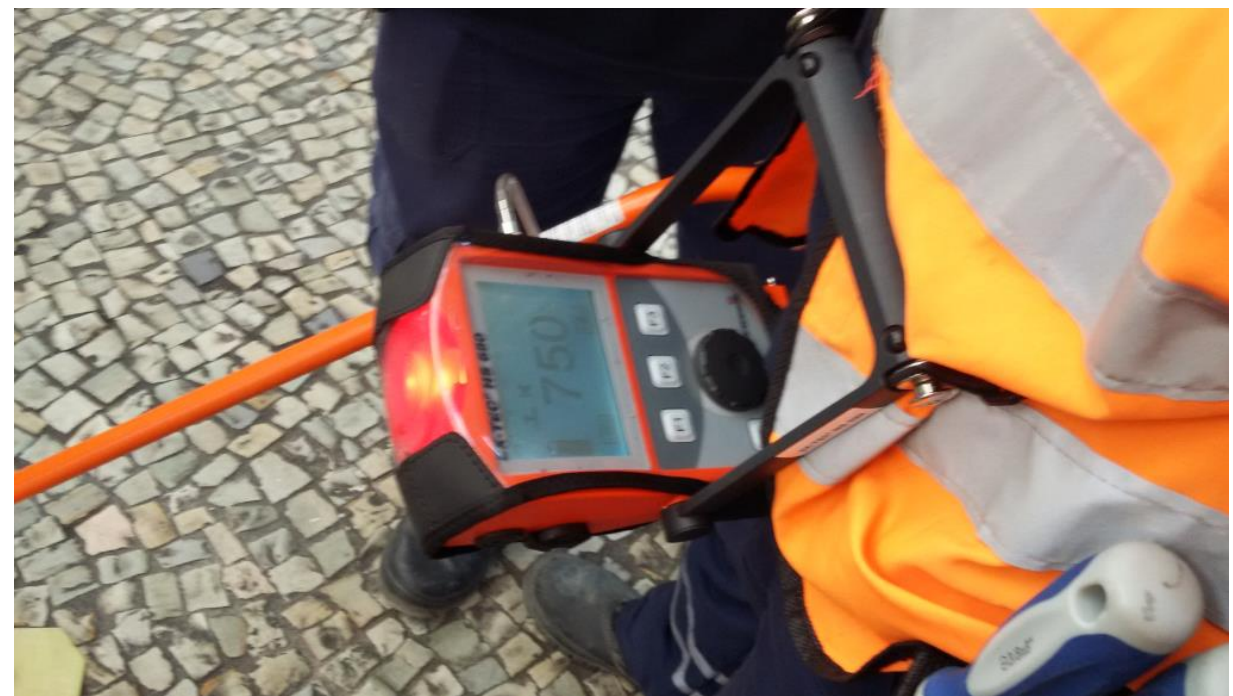

Figura 20 - Medidor mostrando uma leitura de 750 partes por milhão de metano.

Desconsiderando falhas nas calçadas das ruas, nas cidades os vazamentos só podem ser registrados em certos pontos da rede, que são através dos bueiros do chão. Esses bueiros têm ligação direta com o subsolo e qualquer sinal de vazamento de gás é possível captar através deles. Alguns desses bueiros são encontrados quase que impermeáveis devido a fatores externos como chuva, erosão e formação de 
lama em volta do bueiro. Isso dificulta a medição por isso foram usadas chaves de fenda para abrir esses bueiros impermeáveis, como pode ser visto na figura 21 , possibilitando a leitura feita pelos equipamentos.

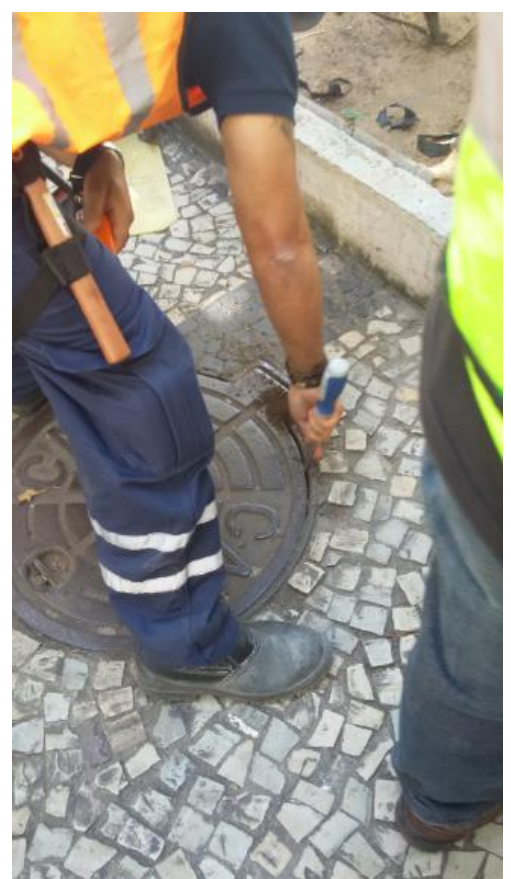

Figura 21 - Utilização de chave de fenda para auxiliar na abertura de bueiros impermeáveis.

Os locais com alto teor de gás natural (gás metano) foram registrados na planta cartográfica, porém ainda não foram identificados os locais exatos dos vazamentos nas tubulações. Se fosse em uma tubulação aérea, a localização exata do vazamento seria encontrada com facilidade, porém em uma tubulação enterrada com presença de asfalto por cima é necessária uma nova etapa. A segunda parte do serviço de detecção de escapamentos é localizar com precisão onde ocorrem os vazamentos para posterior reparo. A figura 22 representa a situação real de um duto enterrado com vazamento.

\section{Bueiro}

Bueiro

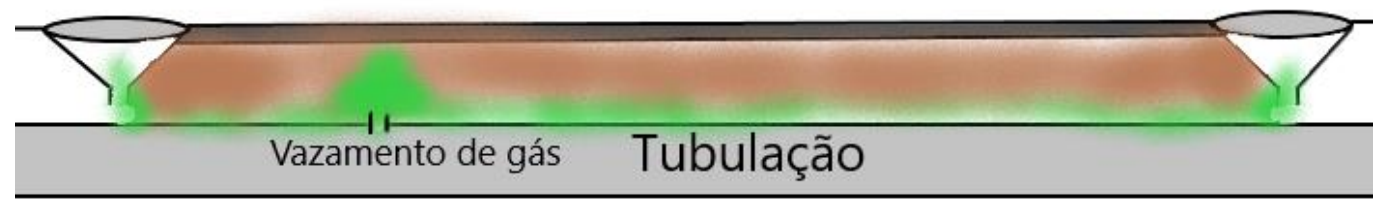

Figura 22 - Desenho esquemático que representa a situação real de um duto enterrado com vazamento.

Diferentemente das tubulações de água onde é possível utilizar aparelhos que captam o mínimo som do vazamento para encontrar o local exato dele, nas tubulações de gás é necessário realizar furos no chão em uma sequência discretizada 
entre os locais de referência onde foram encontrados índices de metano acima de 60 partes por milhão e medir nesses furos o percentual em volume de gás natural para detectar o local exato do escapamento. Quanto maior o volume percentual de gás registrado na leitura, maior será a pressão com que esse gás está sendo expelido para a atmosfera e mais próximo do vazamento se estará. O conhecimento da profundidade da tubulação enterrada é fundamental para realizar o serviço de furação, sem esse conhecimento o serviço deve ser cancelado por segurança devido ao risco de um perigoso acidente causado pelo atrito entre a furadeira e a tubulação.

Após a realização dos furos, utilizou-se a bomba de sucção para retirar o gás acumulado no subsolo com o objetivo de eliminar qualquer interferência que possa atrapalhar nas medições e consequentemente encontrar o local exato do vazamento.

$\mathrm{Na}$ etapa seguinte foram medidos nesses furos o volume percentual de metano (gás natural) e foram realizados novos furos utilizando a técnica da aproximação sucessiva simples para encontrar o local de maior volume percentual de gás, ou seja, o local que apresenta a maior pressão de gás natural do trecho analisado. Os resultados das medições podem ser visualizados na figura 23 , onde estão representados todos os furos feitos no trecho analisado e seus respectivos volumes percentuais de gás.

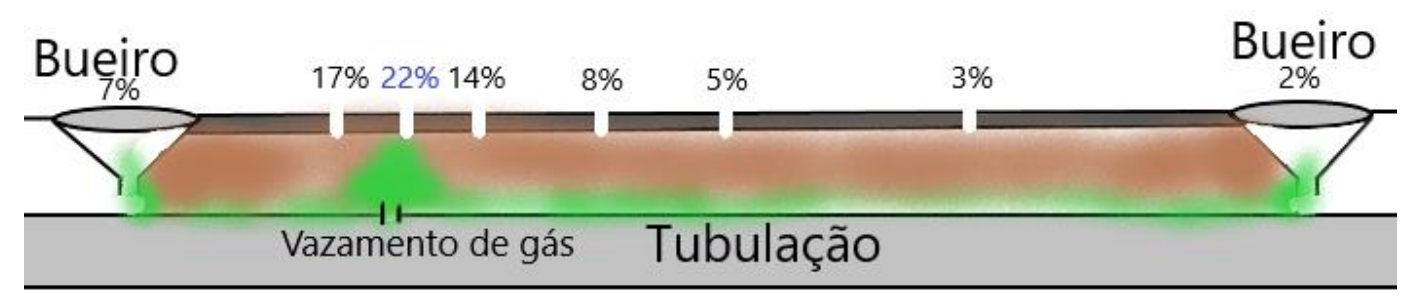

Figura 23 - Desenho esquemático após a realização dos furos e a medição dos volumes percentuais de gás natural em cada um deles.

O furo que apresentou maior volume percentual de gás atingiu um valor igual a $22 \%$, caracterizando o local exato do vazamento na tubulação enterrada, e tal vazamento representa uma fuga de gás nível 2 (vazamento em volume de gás entre $19 \%$ e $89 \%$, sem estar próximo de hospitais ou escolas). Essa medição pode ser vista na figura 24 . 


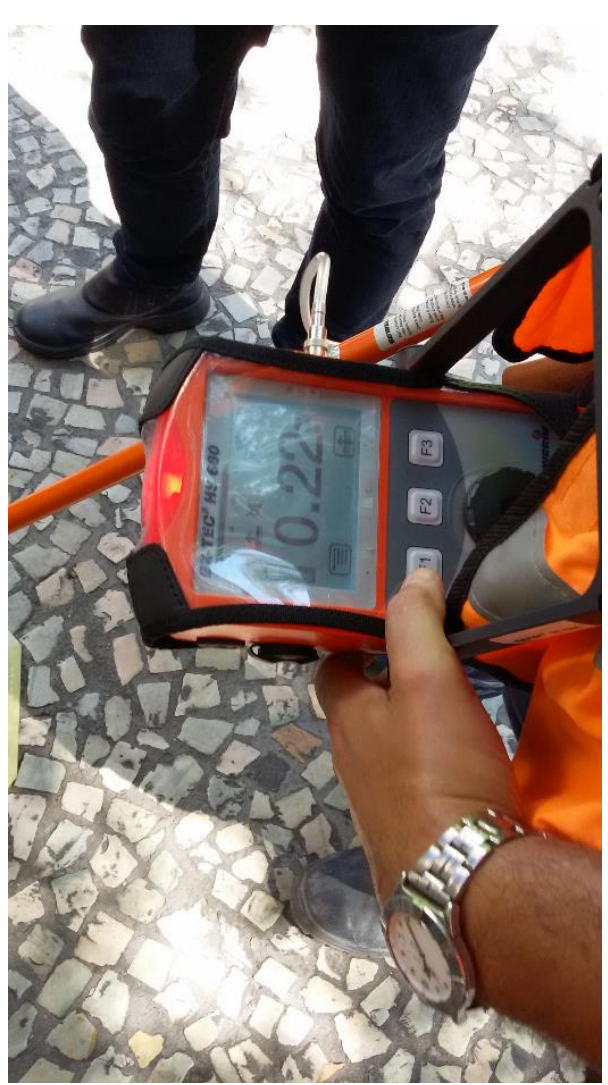

Figura 24 - Medição de $22 \%$ de volume percentual de gás no furo, o maior do trecho.

Dessa forma, o local desse vazamento é registrado na planta impressa para que ele seja adicionado ao aplicativo cartográfico e para que o vazamento seja reparado pelas equipes de manutenção. Como pôde ser visto no capítulo três deste trabalho, uma fuga de nível 2 tem tempo máximo de resolução dependendo da maneira que será removida. Para reparo no vazamento, o tempo máximo de ação é de três meses. E para substituição do trecho com a fuga, o tempo máximo de ação é de seis meses.

Caso o vazamento não seja eliminado no mesmo dia, ele fará parte de uma carteira de fugas da equipe de manutenção. Essa carteira de fugas é um mecanismo de controle através de um arquivo em Excel onde são registradas as novas fugas e também a eliminação das fugas pendentes.

Com as técnicas expostas neste trabalho e com o auxílio dos equipamentos e de pessoas capacitadas e experientes se pode detectar e localizar com precisão um vazamento de gás nas redes de gás natural. 


\section{7. \\ Conclusões}

O gás natural é um combustível mais limpo do que outros combustíveis mais convencionais, por isso é importante que ele seja mais utilizado no mundo e possa até substituir a médio e a longo prazo aqueles que emitem elevada poluição ambiental. Ele é utilizado por indústrias termoelétricas, por automóveis e pelas próprias famílias em suas respectivas casas.

Para distribuir o gás natural para seus consumidores é necessária uma rede de tubulações ao mesmo tempo em que essa distribuição deve acontecer de forma segura. Sabe-se que o gás natural é altamente inflamável e por isso são necessárias inspeções periódicas para detectar possíveis vazamentos de gás nas redes de distribuição de gás.

Este trabalho demonstra como funciona um serviço de detecção de escapamentos de gás utilizando sensores que detectam na atmosfera o metano, o qual, como já foi visto, faz parte de $89,0 \%$ em volume do gás natural. O serviço que é realizado pela equipa de manutenção pode detectar um vazamento de gás em uma tubulação enterrada e através das técnicas demonstradas neste trabalho é possível encontrar o local exato do vazamento.

A tecnologia apresentada para realizar o serviço de detecção não existia há algumas décadas, da mesma forma que novas tecnologias podem surgir nos próximos anos para facilitar e criar novas formas para detectar os escapamentos de gás. Mesmo atualmente é possível imaginar com o auxílio de equipamentos eletrônicos uma forma de vigiar e controlar em tempo real certos dados do escoamento como pressão e temperatura e através deles deduzir se está ou não ocorrendo algum vazamento de gás. Há muito o que estudar e testar para que se tenha um sistema de inspeção com ainda mais qualidade e segurança. 
8. Referências Bibliográficas

[1] MONTEIRO, J. V. de F.; DA SILVA, J. R. N. M.. Gás natural aplicado à indústria e ao grande comércio. Blucher. COMGAS Natural. 2010.

[2] IBAMA. Conselho Nacional do Meio Ambiente. Resolução Conama n. 001, de 23 de janeiro de 1986 - Estabelece as definições, as responsabilidades, os critérios básicos e as diretrizes gerais para uso e implementação da Avaliação de Impacto Ambiental como um dos instrumentos da Política Nacional do Meio Ambiente. Brasília, 1986.

[3] AGENERSA. Agência Reguladora de Energia e Saneamento Básico do Estado do Rio de Janeiro.

[4] Equipamentos Portáteis de Detecção.

(http://www.bvsde.paho.org/cursode/p/modulos/modulo_3.2.pdf em outubro/2017), por Anderson Pioli, Jorge Luiz Nobre Gouveia e Agnaldo Ribeiro de Vasconcellos.

[5] SEWERIN. Technologies for leak detection.

(https://www.sewerin.com/cms/en/start.html em outubro/2017). 
[6] Norma Regulamentadora 6 - NR6. Equipamento de Proteção Individual EPI. (http://www.guiatrabalhista.com.br/legislacao/nr/nr6.htm em outubro/2017). 